\title{
First Republic radiology contest for foreign students of medical schools in Kyrgyz Republic
}

Aliya Kadyrova, Begaiym Kulbaeva, Nurgasibat Musaeva, Cholpon Turatbek, Jitendra Mahato, Anil Kumar Shah Radiology Department of I.K. Akhunbaev's Kyrgyz State Medical Academy

Bishkek, Kyrgyz Republic

On January 28, 2022, the first International Radiology Contest for Foreign Students of Medical Schools in Kyrgyzstan was held. Long-awaited event, which took two years to establish due to pandemic, was finally organized and hosted by Radiology Department of I.K. Akhunbaev's Kyrgyz State Medical Academy (KSMA). In the list of guested participants were teams from KSMA, the International Higher School of Medicine (ISHM); B. N. Yeltsin Kyrgyz-Russian Slavic University (KRSU) and S. Tentishev Asian Medical Institute (AsMI).

Alas, pandemic has made its contribution to the life of each of us, including reconsidering the importance of certain professions. In Western countries imaging techniques are skillfully used by doctors of various specialties and diagnosis is inconceivable without radiology. While in Kyrgyzstan radiology was historically regarded as "optional» specialty, and clinicians did not always reckon the opinion of radiologists. And only after the summer of 2020, radiology demonstrated its significance and revealed some problems. Other issue is not only about absence of advanced imaging techniques, but deficiency of experienced staff throughout the country.

Therefore, main idea behind Radiology Contest is to popularize discipline among students and provide an opportunity to study deeper. Moreover, not only compete in their knowledge of the discipline, but also to reveal hidden talents, showcase it and promote creativity. And all the teams did a great job!

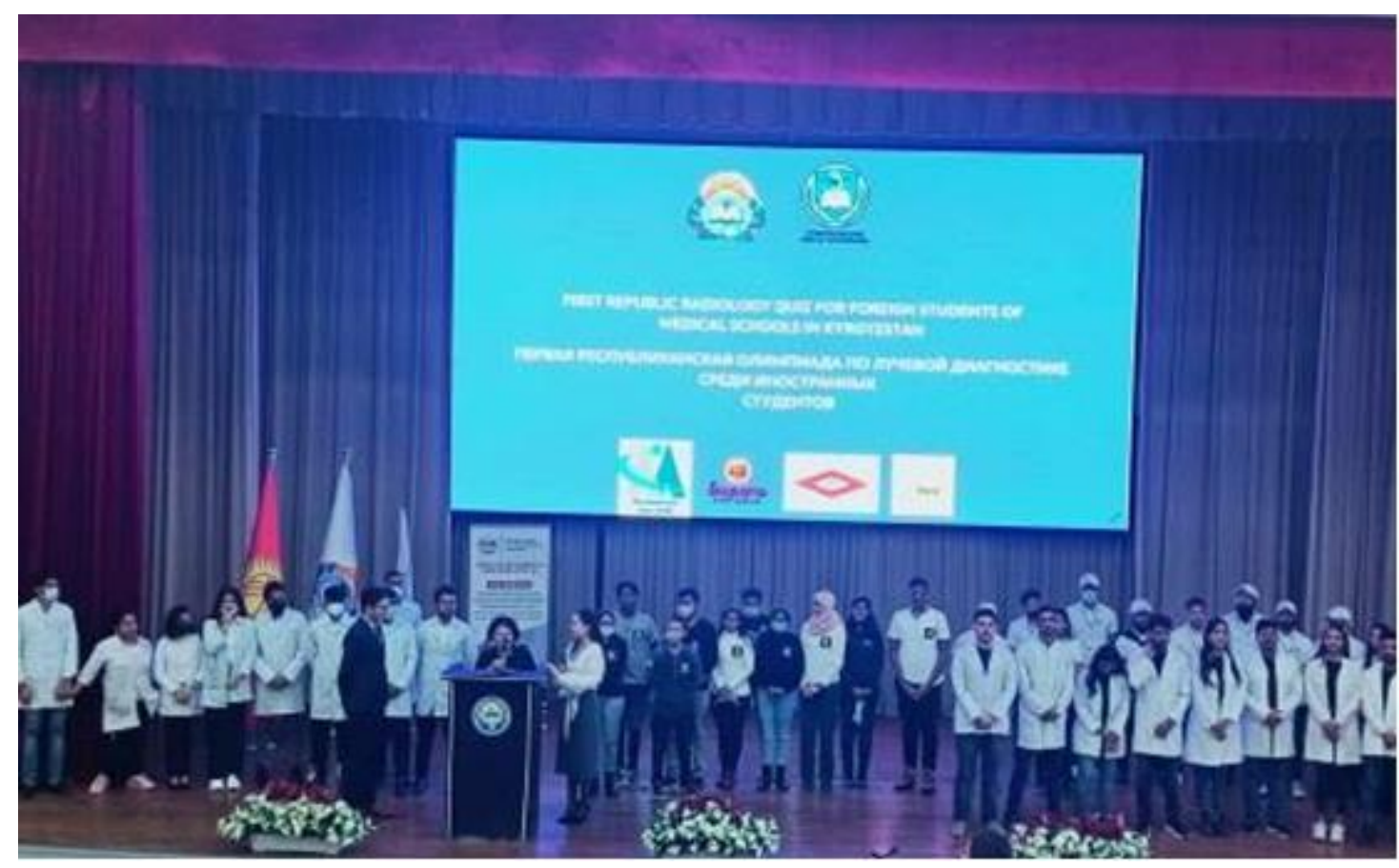

Figure 1. Greetings from vice-rector for the tate language and educational work Zhunushalieva Gulsunkan Ishengazievna

Address for Correspondence: Aliya Kadyrova, Department of Radiology, I.K. Akhunbaev Kyrgyz State Medical Academy, 92A, Akhunbaev str., 720020, Bishkek, Kyrgyz Republic Email: al-kadyrova@yandex.ru

I.K. Akhunbaev Kyrgyz state medical academy, Radiology department

Received: 06.02.2022 Revised: 20.02.2022 Accepted: 21.02.2022

Copyright @2022 Heart, Vessels and Transplantation 
Therefore, First Republic Radiology Contest for Foreign Students of Medical Schools in Kyrgyz Republic has begun.

An intense battle for the championship took place between "AZMI'tes» from AsMI, "Magnet-ISHM» from IHSM, «Te Gray OWLS» from KRSU and «Sigma» from KSMA.

The vice-rector for the state language and educational work Gulsunkan Ishengazievna Zhunushalieva delivered a welcoming speech, after which the presenters held a draw (Fig.1). The event began with greetings and instructions from the head of the
Radiology department, associate professor Aliya Kadyrova. The radiology contest was conducted in English and was divided into five rounds as «Introduction Round», «Rapidfire Round», "Clinical Case Round", "Homework (Creativity/Humor/Knowledge)» and "Captain's Competition Round».

The judges from Radiology Department of all four Universities participated, evaluated the work of teams and gave points according to performance of each team (Fig. 2).

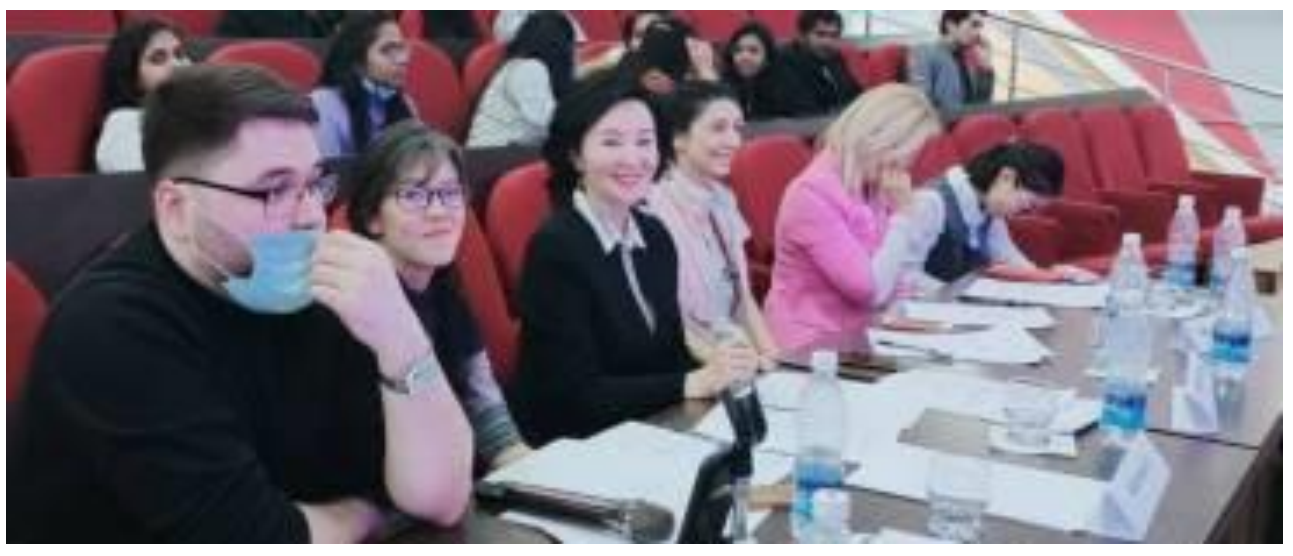

Figure 2. Panel of judges composed radiologists and representatives from each of the universities. From left to right: Begaiym Nurlanbekovna Kulbaeva and Aliya Ishenbekovna Kadyrova, as head of judges. Oksana Vladimirovna Skorobogatova from ISHM and Safiyat Suleymanovna Emiroslanova from AsMI

In the first competition, each team introduced themselves. They presented themselves to judges and the audience through video, sketches, performance or dance. The humor and presentation on the theme of radiology were appreciated. Duration of round was 10 minutes for each team.

The KSMA team (Sigma from KSMA) made a modest video with a traditional performance. Second video was by the KRSU team (Te Gray OWLS), which best conveyed the daily activities of radiologists. Third presentation was performed by IHSM (Magnet-IHSM) with a nice sketch full of humor, about the importance of the profession (Fig. 3). However, we would like to particularly highlight charismatic AsMI team (AZMI'tes), demonstrated a brilliant video about unlucky patient and working routine of doctors.

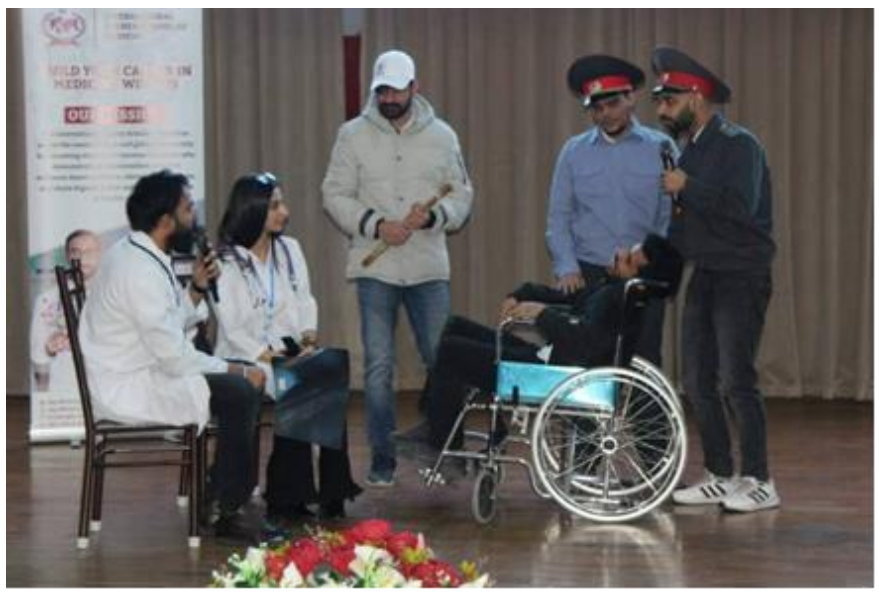

Figure 3. Performance of Magnet-IHSM team (ISHM), first round. 
After relaxing and funny first competition, second, "Rapidfire round" has started. Truly harsh limit-test of each participant: strict time limits, 7 theoretical and 8 images related to variety of imaging modalities of well-known, but completely random, pathologies. In time period of 20 seconds, team should decide which answer is correct, but contest additional questions, if some time left. With total time limit of 5 minutes, competition demonstrated confidence of participants and competitiveness. All teams have shown themselves as close-knit teams and were "breathing down each other's necks", although Sigma was slightly behind.

Although previous competition was intense due to limitations, following "Clinical Case round" was a reflection of all accumulated experience and clinical thinking development. Tasks were designed as close as possible to casual activity: minimal patient's data with indirect clues and multiple images. Main goal here was to outline radiological signs, establish a conclusion, form correct differential diagnosis and assign additional examination, if necessary. So if previous competition was an opportunity of each teammate to shine in specific questions, so "Clinical case" was to represent their teamwork. A crucial skill in the future doctor's career. Again, all the teams were at the top and proved that they are worthy examples of their universities. It was really difficult to find the best team.

To take some time-out from intense mental activity, the next competition was "Homework», similar to Club of the Funny and Inventive. Main topic here was, obviously, Radiology and highly demanding of their creativity, humor and knowledge. The teams approached it differently. KSMA team was worth mentioning; whose members prepared a romantic comedy skit. A heartbreaking (actually!) story in several acts, about rejected young man, suffering and seeking for help of the doctors. Sigma delightfully added radiology as a vehicle, showing broken heart in each modality with happy-ending.

Lastly, "Captain's Competition Round" was held as an individual practical contest. Captains of each team participated displaying skills of conducting ultrasound examination and demonstrating anatomy knowledge (Fig. 4). Anshuman Panday of the Sigma team showed excellent work and added extra points to his team.

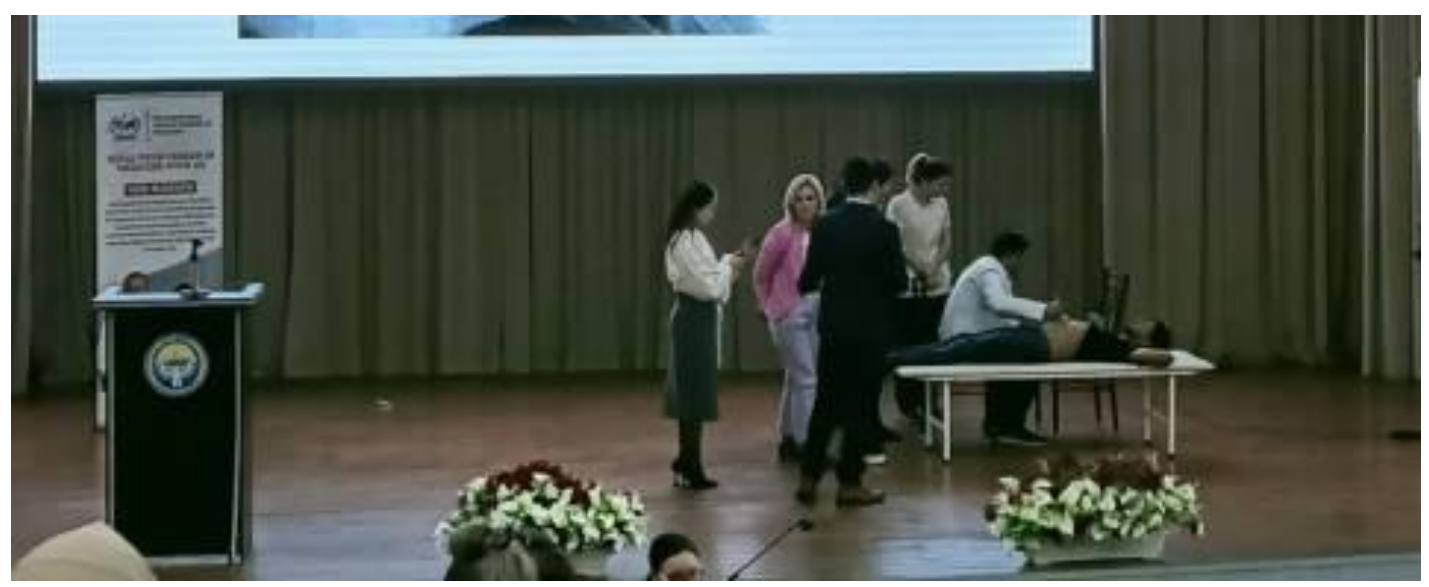

Figure 4. Captain's Competition Round. The judges are evaluating the skills of participants in ultrasound.

Final counts have been made, places - distributed and awarding ceremony has begun.

Fourth place won by the team "AZMI'tes» of AsMI, a team that surprised everyone with its deepest theoretical knowledge, teamwork and strong-bond.

Team "Magnet-ISHM» from ISHM took the third place. Most charismatic team won the jury and the audience hearts with their artistry from the first minutes on stage and kept up with other teams.
Team «Te Gray OWLS» of KRSU took second place by a small margin. They proved themselves as strongest opponents, who burst swiftly into the Contest willing to win.

Team "Sigma» of Kyrgyz State Medical Academy became the winner of First Radiology Contest for foreign students of medical schools in Kyrgyzstan.

Commemorative certificates were presented to each team member and gratitude letters - to their mentors (Fig. 5, 6). 


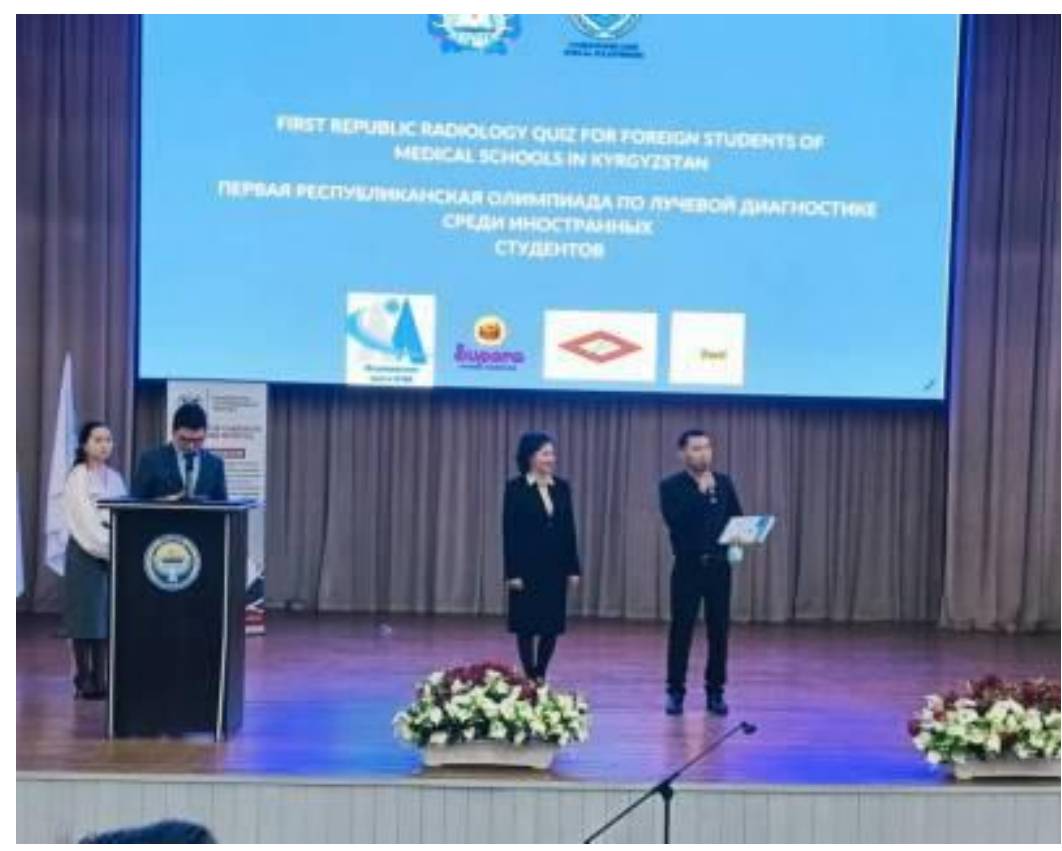

Figure 5. Dean of foreign student's faculty of I.K. Akhunbaev's KSMA, Tugolbai Tagaev, and Head of the Judges, Aliya Kadyrova, at team awards ceremony.

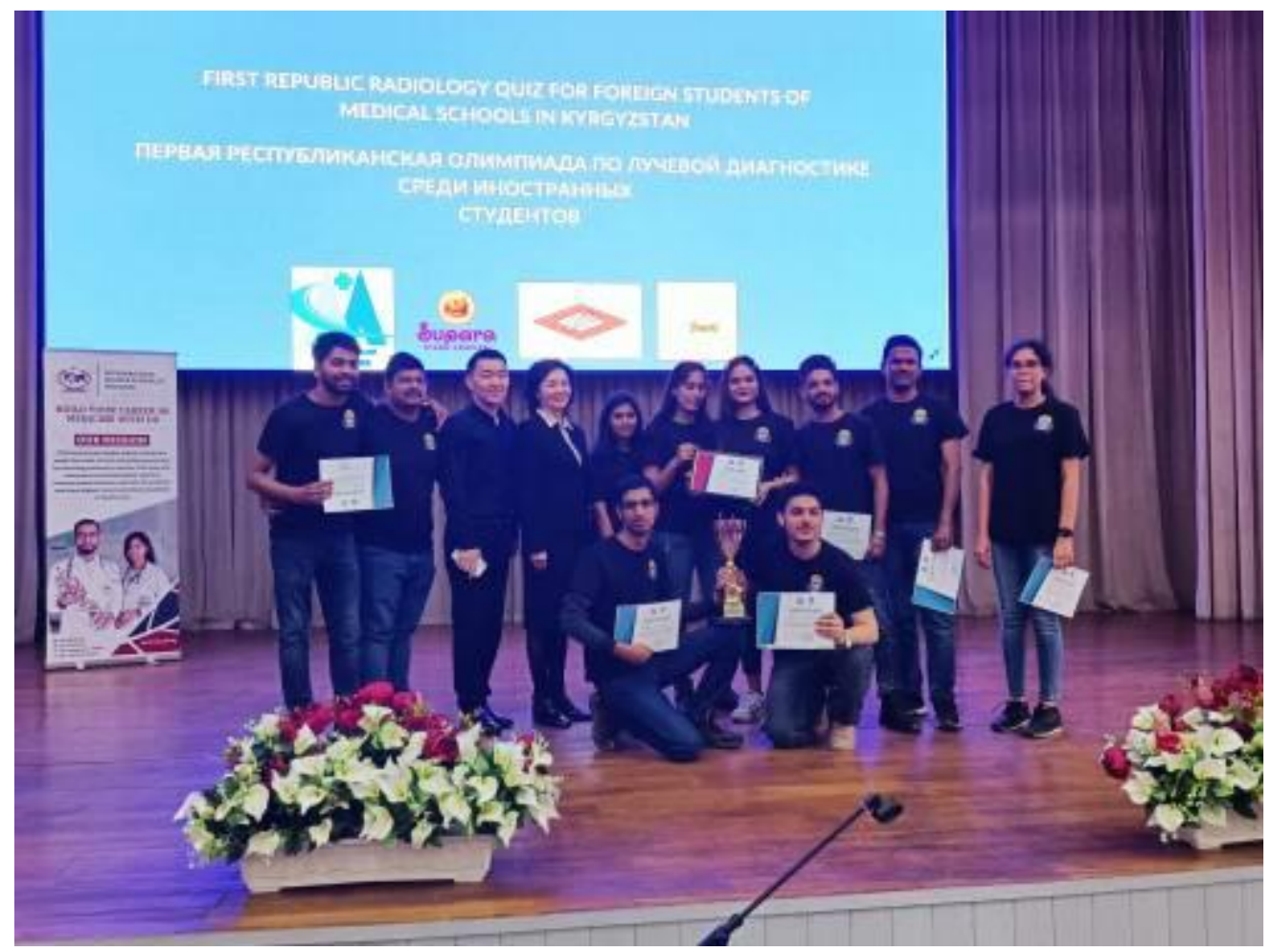

Figure 6 . Victory was not easy, but it proves once again that above all is not one person's knowledge, but it's the ability to work as a team 
We would like to express our special thanks to the sponsors of the Contest, which would be impossible without their participation: Medical Center of KSMA, Ethno-complex «Supara», «Shoro» company and Ulush Travel.

Thus, the first ever International radiology contest for foreign students of medical schools in Kyrgyzstan ended with great emotions, inspiration, celebrations with team members, taking collective pictures and planting seeds of the friendship.
Certainly, contestants will put a lot of effort into keeping the lead in upcoming competitions.

The staff of the Radiology Department of I.K Akhunbaev's Kyrgyz State Medical Academy wishes success and all the best, and hopes that the international radiology contest for foreign students will become a good tradition.

Peer-review: Internal and external Conflict of interest: None to declare Authorship: A.K., B.K., N.M., Ch.T., J.M., and A.K.Sh. are equally contributed to preparation of article Acknowledgement and funding: None to declare

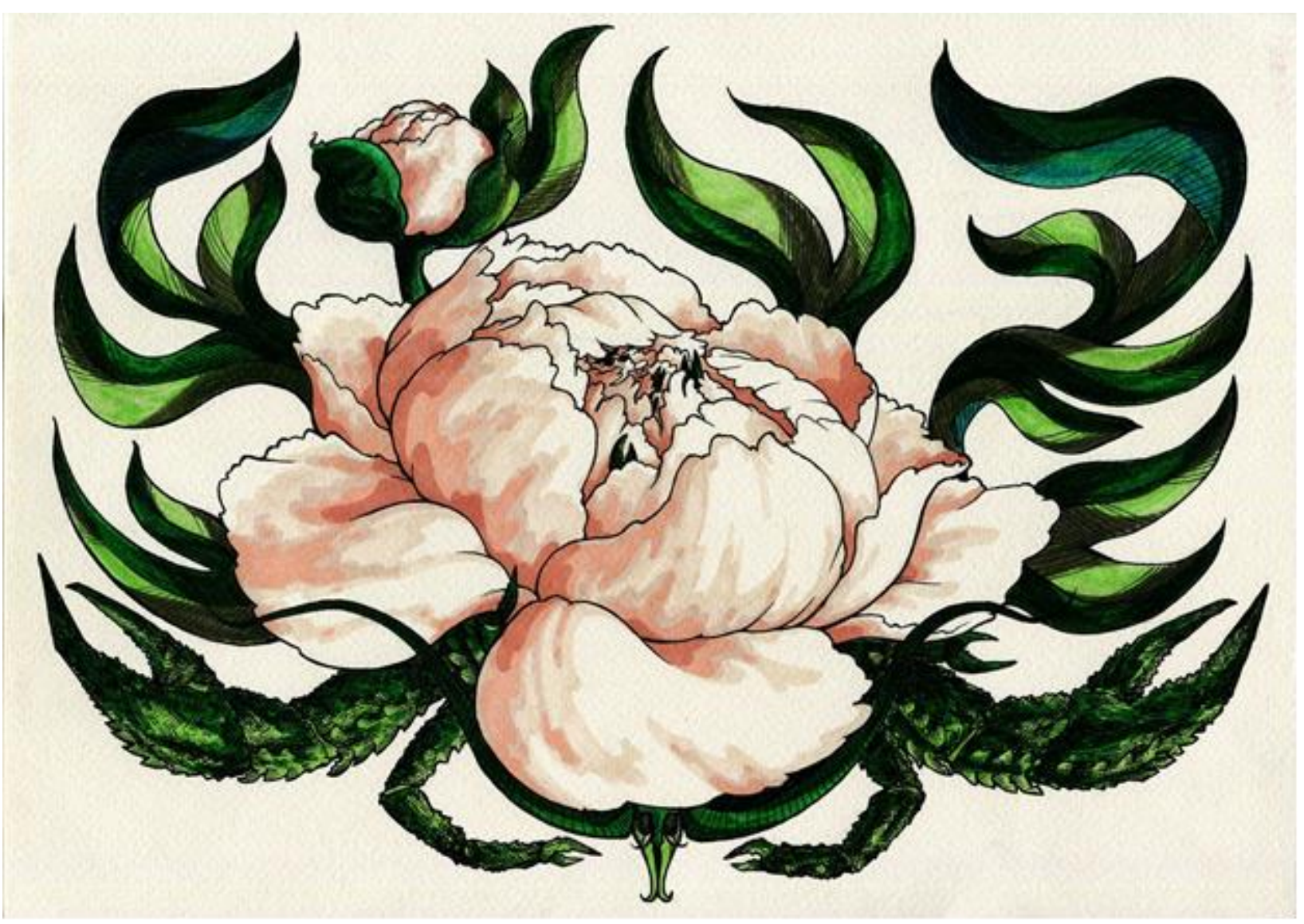

"T1NOMO" Cancer is difficult to detect in time, because for a long time it can be asymptomatic, hidden. Tetiana Antypova, Student`s Club, Bukovinian Medical University, Chernivtsi, Ukraine 